\title{
Leukocyte presence does not increase microbicidal activity of Platelet-rich Plasma in vitro
}

\author{
Erminia Mariani ${ }^{1}{ }^{2}$, Valentina Canella ${ }^{1}$, Andrea Berlingeri ${ }^{4}$, Alessandra Bielli ${ }^{4}$, Luca Cattini ${ }^{1}$, Maria Paola Landini ${ }^{4}$,
} Elizaveta Kon ${ }^{3}$, Maurilio Marcacci ${ }^{3}$, Berardo Di Matteo ${ }^{3}$ and Giuseppe Filardo ${ }^{3}$

\begin{abstract}
Background: Human platelets are a rich reservoir of molecules that promote regenerative processes and microbicidal activity. This activity might be increased by concentration in platelet-rich plasma (PRP) products and modulated by the presence of leukocytes. Despite extensive use in clinical procedures, only few studies have investigated PRP's real microbicidal potential. Therefore, this study aimed at comparing the in vitro microbicidal activity of platelets and leukocyte-enriched PRP (L-PRP) to pure platelet-rich plasma (P-PRP) and the contribution of leukocytes to microbicidal properties.

Antimicrobial effects of P- and L-PRP were tested against Escherichia Coli, Staphylococcus Aureus, Klebsiella Pneumoniae, Pseudomonas Aeruginosa and Enterococcus Faecalis. Furthermore, L-PRP was frozen (L-PRP cryo) to assess whether the preparation maintained in vitro characteristics. Microbicidal proteins released by the three preparations were also evaluated.

Results: L-PRP, L-PRP cryo and P-PRP generally induced comparable bacterial growth inhibition for up to $4 \mathrm{~h}^{\prime}$ incubation, range 1-4 log. MIP-1a, RANTES, GRO-a, IL-8, NAP-2, SDF-1a and IL-6 showed strong microbicidal potential.

Conclusions: We found in vitro antibacterial activity of L-PRP and P-PRP and the possibility to cryopreserve L-PRP, without important changes to its effectiveness; similar microbicidal activity between preparations containing or not leukocytes; and the contribution of three new molecules (NAP-2, SDF-1a and IL-6).
\end{abstract}

Keywords: Platelet-rich plasma, Leukocytes, Bacterial growth inhibition, Antimicrobial activity, Microbicidal proteins, Nosocomial infections

\section{Background}

Human platelets are a rich reservoir of molecules and growth factors that can promote regenerative processes $[1,2]$ and stimulate tissue healing by the local release of platelet-derived growth factors and other bioactive molecules [3-6]. In addition, platelets have been associated with antibacterial host defense [7-10], due to the release of platelet microbicidal proteins (PMP) [11] and multiple chemokines that, sharing molecular structures (CC or

\footnotetext{
* Correspondence: erminia.mariani@unibo.it

'Laboratory of Immunorheumatology and Tissue Regeneration/RAMSES,

Rizzoli Orthopaedic Institute, Via di Barbiano 1/10, 40136 Bologna, Italy

${ }^{2}$ Department of Medical and Surgical Sciences, University of Bologna,

Bologna, Italy

Full list of author information is available at the end of the article
}

CXC motifs) with multiple antimicrobial peptides (AMP), result in the double role of chemoattractant and microbicidal proteins $[12,13]$.

These proteins act as a first line of defense against invading micro-organisms and molecules released after platelet activation are also able to recruit cells (e.g. leukocytes), thus modulating in vivo multiple physiological processes [8].

The antibacterial potential of platelets might be increased through their concentration in platelet-rich plasma (PRP) products, thus making these bloodderivatives good candidates for preventing operative and post-operative infections, and avoiding the risk of immunological reactions because of their autologous 
origins. Accordingly, in recent decades various types of PRP preparations have been developed, from pure platelet-rich plasma (P-PRP, characterized by the presence of platelets only) to leukocyte- and platelet-rich plasma (L-PRP) $[14,15]$. As leukocytes play an important role in the innate host-defense, the antibacterial effects of plasma enriched in platelets and leukocytes might have increased microbicidal activity compared to the fractions containing platelets alone [16].

Unfortunately, despite the extensive use of such compounds in a variety of surgical and clinical procedures [17-21], up to now only few studies have investigated platelet microbicidal activity [22-26] and, therefore, the real antibacterial potential of PRP. In addition, the many protocols for PRP preparation, the possibility to include different cellular components in various proportions and the lack of a consensus terminology (so that different acronyms identify similar preparations) make the definition of PRP biological and antibacterial properties difficult $[15,27,28]$.

Accordingly, the purpose of the current study was to investigate the in vitro microbicidal activity of a bloodderivative enriched in platelets and leukocytes (called $\mathrm{L}-\mathrm{PRP}$ ) compared to pure platelet-rich plasma (P-PRP), to assess their effects and the contribution of the leukocyte component to the antibacterial properties.

The microbicidal activities of P-PRP and L-PRP were tested against Escherichia Coli, Staphylococcus Aureus, Klebsiella Pneumoniae, Pseudomonas Aeruginosa and Enterococcus Faecalis, as species potentially involved in bone, soft tissue and wound infections $[29,30]$ and representing the strains more commonly involved in nosocomial infections.

In addition, since haemoderivatives can be used for patients treatment after collection and storage, L-PRP was also frozen and then thawed to obtain the cryopreserved L-PRP (L-PRP cryo), to assess whether the preparation maintained its in vitro characteristics against the selected bacteria.

We showed similar in vitro antibacterial activity of L-PRP and P-PRP against the selected bacteria, and the possibility to cryopreserve L-PRP without important changes to its effectiveness. The contribution of three new molecules (NAP-2, SDF-1 $\alpha$ and IL-6) as antimicrobial peptides have also been evidenced.

\section{Methods \\ Donors}

Ten healthy men (mean age \pm SD: $29.9 \pm 3.4$ years), enrolled on a voluntary basis, signed a written informed consent form to participate in the study protocol which was approved by the Rizzoli Orthopedic Institute Ethic Committee.
Subjects with smoking habits, taking non-steroidal anti-inflammatory drugs for 5 days before blood collection, suffering from systemic disorders and/or infections, or with hemoglobin concentrations $<11 \mathrm{~g} / \mathrm{dl}$ and platelet numbers $\leq 150 \times 10^{3} / \mu \mathrm{l}$, were excluded from the study. Code numbers assigned to the samples assured subject anonymity.

\section{Blood-derivative preparation}

P-PRP was prepared following a one-step procedure. Briefly, $45 \mathrm{ml}$ of venous blood was collected from each subject in five tubes containing $1 \mathrm{ml}$ of sodium citrate solution $(3.8 \%)$ as anticoagulant and centrifuged at $460 \mathrm{~g}$ for $8 \mathrm{~min}[31,32]$, thus obtaining three layers: platelet-poor plasma (PPP) on the top of the tube, P-PRP in the middle and erythrocytes at the bottom of the tubes. In sterile conditions, about $1 \mathrm{ml} /$ tube of P-PRP, located on the red blood cell pellet, was carefully harvested avoiding leukocyte collection.

L-PRP was prepared following a two-step procedure. Briefly, $150 \mathrm{ml}$ of venous blood was collected from each subject in a sterile plastic bag containing $21 \mathrm{ml}$ of citrate-phosphate-dextrose as anti-coagulant. After a first centrifugation step at $730 \mathrm{~g}$ for $15 \mathrm{~min}$ to separate erythrocytes, the fraction located on the red blood cell pellet was transferred in a second bag via a closed circuit and underwent a second centrifugation at $3800 \mathrm{~g}$ for $10 \mathrm{~min}$, thus obtaining two separate layers: plateletpoor plasma (PPP), on the top of the bag and L-PRP (a concentrate of platelets and leukocytes) at the bottom. In sterile conditions, the L-PRP fraction was carefully harvested [32]. One aliquot of L-PRP was frozen at $-30{ }^{\circ} \mathrm{C}$ for $2 \mathrm{~h}$ and then thawed thus obtaining the cryopreserved fraction (L-PRP cryo).

\section{Activation of platelet concentrates}

Two aliquots of P-PRP, L-PRP and L-PRP cryo from each donor were activated by the addition of $10 \%$ calcium chloride $\left(\mathrm{CaCl}_{2}\right.$, final concentration: $\left.22,8 \mathrm{mM}\right)$ and incubated for $1 \mathrm{~h}$ and $18 \mathrm{~h}$ at $37^{\circ} \mathrm{C}$ in $5 \% \mathrm{CO}_{2}$, corresponding, respectively, to the first and last time-point of bacterial incubation. After incubation, PRP samples were centrifuged $\left(15 \mathrm{~min}\right.$ at $2800 \mathrm{~g}$ at $\left.20^{\circ} \mathrm{C}\right)$ and supernatants were collected and frozen at $-30 \mathrm{C}^{\circ}$ until use.

\section{Quantification of microbicidal proteins release}

For the evaluation of microbicidal proteins, P-PRP, L-PRP and L-PRP-cryo from each donor were assayed in duplicate. Commercially available multiplex bead-based sandwich immunoassay kits were used to simultaneously evaluate the following soluble factors: Macrophage Inflammatory Protein (MIP)-1 $\alpha$ (CCL3), Regulated on Activation Normal $\mathrm{T}$ Expressed and Secreted protein (RANTES) (CCL5), GRO- $\alpha$ (CXCL1), Interleukin (IL)-8 (CXCL8), Interleukin 
(IL)-6 (Bio-Rad Laboratories, CA, USA); neutrophilactivating protein (NAP)-2 (CXCL7), stromal cell-derived factor (SDF)-1 $\alpha$ (CXCL12) (Milliplex MAP Kit, Millipore, Bedford, MA), as previously described [33, 34]. Briefly, distinct sets of fluorescently dyed beads loaded with capture monoclonal antibodies, specific for each cytokine to be tested, were used. Samples or standards (diluted according to the manufacturer's recommendations) or standards (50 $\mu \mathrm{l} /$ well) were incubated with $50 \mu \mathrm{l}$ of pre-mixed bead sets inside the wells of a 96-well microtiter plate.

The formation of different sandwich immune complexes on distinct bead sets was measured and quantified by using the Bio-Plex Protein Array System (Bio-Rad Laboratories, USA). A $50 \mu$ l volume was sampled by each well and the fluorescent signal of a minimum of 50 beads per region (chemokine/cytokine) was evaluated and recorded. Values with a coefficient of variation above the $10 \%$ were discarded before the final data analysis.

Data were analyzed by the Bio-Plex Manager software version 6.0 (Bio-Rad Laboratories, USA). Standard levels between 70 and $130 \%$ of the expected values were considered to be accurate and were used. In general, at least six standards were accepted and used to establish standard curves following a Five-Parameter Logistic (5-PL) regression model. Sample concentrations were immediately interpolated from the standard curves.

\section{Determination of platelet and leukocyte numbers}

Platelet and leukocyte count was performed by the Coulter LH 750 (Beckman Coulter Inc. Miami, Fl, USA) automated hematology analyzer. Linearity was 5-1000 $\times$ $10^{3} / \mu \mathrm{l}$ for platelet count and $0.1-100 \times 10^{3} / \mu$ l for white blood cell count.

The median platelet number was $861 \times 10^{3} / \mu$ l (interquartile range 715 - $959 \times 10^{3} / \mu \mathrm{l}$ ) in L-PRP; $290 \times 10^{3} / \mu \mathrm{l}$ (interquartile range $\left.182-385 \times 10^{3} / \mu \mathrm{l}\right)$ in P-PRP; $275.5 \times 10^{3} / \mu \mathrm{l}$ (interquartile range $207-484 \times 10^{3} / \mu \mathrm{l}$ ) in L-PRP cryo. The median leukocyte count was $<0.2 \times 10^{3} / \mu \mathrm{l}$ in P-PRP; $5.450 \times 10^{3 /} \mu \mathrm{l}$ (interquartile range $5.050-6.425 \times 10^{3} / \mu \mathrm{l}$ ) in L-PRP; $0.550 \times 10^{3} / \mu$ l (interquartile range $0.425-1.275 \times$ $\left.10^{3} / \mu \mathrm{l}\right)$ in L-PRP cryo.

\section{Preparation of bacterial stocks}

Bacterial species were obtained from the Bioresource Collection of the American Type Culture Collection (ATCC, Manassas, VA, USA), chosen according to morphological characteristics of membrane and growth [35] and as species implicated in bone and soft-tissue infections $[29,30]$.

Three Gram negative (Escherichia coli, ATCC 25922; Pseudomonas aeruginosa ATCC 27853; Klebsiella pneumoniae ATCC 700603) and two Gram positive (Staphylococcus aureus, ATCC 29213 and Enterococcus faecalis, ATCC 29212) bacterial strains were selected.
From a starting suspension of $10^{8}$ colony-forming units $(\mathrm{CFU}) / \mathrm{ml}$ in Tryptic Soy Broth medium (TSB, MEUS S.R.L., Italy), 10 -fold serial dilutions $\left(10^{6}, 10^{5}\right.$ and $10^{4} \mathrm{CFU} / \mathrm{ml}$ ) were prepared, thus obtaining bacterial concentrations mirroring a localized infection in vivo $[23,36]$.

\section{Plating assay and bacterial count}

In sterile conditions, P-PRP, L-PRP and L-PRP cryo $(90 \mu \mathrm{l})$, obtained from each donor were activated with $10 \mu \mathrm{l}$ of $\mathrm{CaCl}_{2}$ (22.8 mM final concentration) and added to $900 \mu \mathrm{l}$ of each bacterial dilution to be tested $\left(10^{4}, 10^{5}\right.$, $\left.10^{6} \mathrm{CFU} / \mathrm{ml}\right)$. Tubes were mixed vigorously and then incubated at $37{ }^{\circ} \mathrm{C}$ for $1,2,4$ and 18 h respectively. TSB was used as control condition.

After incubation, $10 \mu \mathrm{l}$ of each bacterial suspension was spread on Blood Horse Agar (MEUS S.R.L., Italy) using a seeding distributed in 3 quadrants with an appendix in terminal part (Fig. 1). Agar plates were incubated at $37^{\circ} \mathrm{C}$ for $18-24 \mathrm{~h}$, then a semi quantitative estimation of bacterial growth $(\mathrm{CFU} / \mathrm{ml})$ was performed by counting the colonies in each quadrant (Table 1).

\section{Statistical analysis}

Values are presented as medians, interquartile ranges and percentage, as appropriate.

The antimicrobial activity is calculated as difference between experimental conditions and control culture conditions and reported as log of growth inhibition. Data are expressed as percent frequency of subject displaying a certain inhibition.

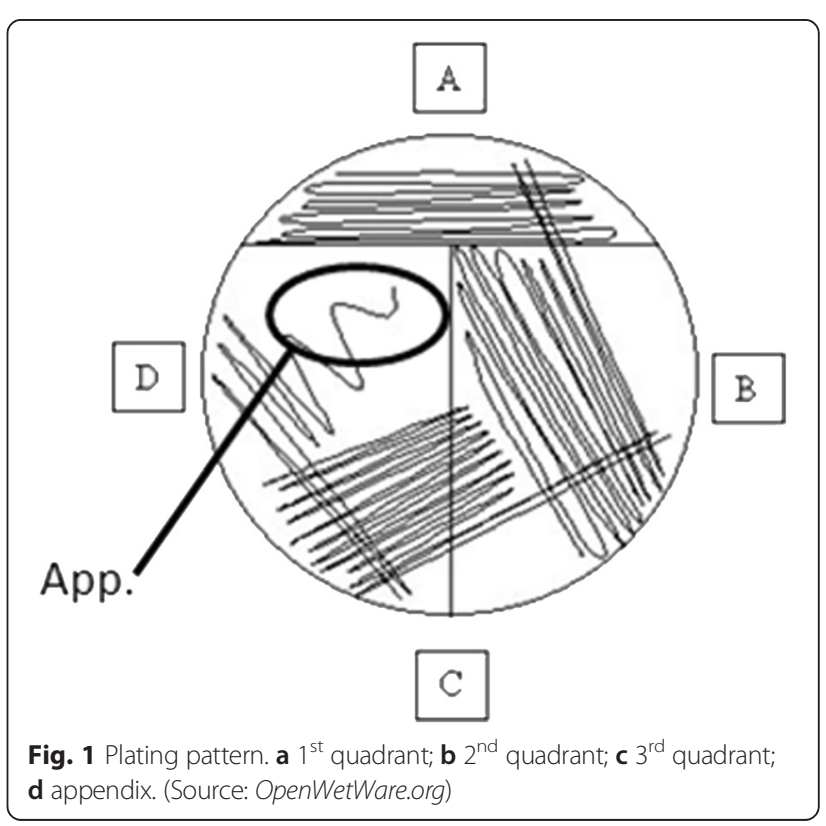


Table 1 Semi-quantitative estimation of bacterial growth (CFU/ml)

\begin{tabular}{lllllll}
\hline Number of quadrant & \multicolumn{3}{l}{ Colony count } \\
\hline $1^{\text {st }}$ quadrant & 0 & $1-4$ & $\geq 5$ & $\geq 5$ & $\geq 5$ & $\geq 5$ \\
$2^{\text {nd }}$ quadrant & & & $<5$ & $\geq 5$ & $\geq 5$ & $\geq 5$ \\
$3^{\text {rd }}$ quadrant & & & & $<5$ & $\geq 5$ & $\geq 5$ \\
Appendix & & & & & 0 & $\geq 1$ \\
Approximate growth $(\mathrm{CFU} / \mathrm{ml})$ & $<10^{3}$ & $10^{3}$ & $10^{4}$ & $10^{5}$ & $10^{6}$ & $>10^{6}$
\end{tabular}

Bacterial growth was determined by the number of colonies detected on each agar plate

Differences in growth inhibition among incubation times, types of treatment and number of seeded bacteria were analyzed using the Friedman-Anova test. Differences between two culture conditions were analyzed by the Wilcoxon-matched pair test.

Correlations between concentrations of released soluble factors and the growth inhibition of each bacterium strain at the different time points were analyzed by means of the Kendall-Tau rank correlation test.

The level of statistical significance was set at $\mathrm{p}<0.05$ and adjusted according to Bonferroni's correction for multiple comparisons $(\mathrm{p}<0.017)$, as appropriate. Data were analyzed using the Statistica 6 software (StatSoft. Inc., Tulsa, USA).

\section{Results}

\section{Bacterial growth inhibition}

In general, bacterial growth inhibition produced by the three PRP preparations lasted for up to $4 \mathrm{~h}$ of incubation, and ranged between 1 and $4 \log$ (corresponding to inhibitions from 10 to $10.000 \mathrm{CFU} / \mathrm{ml}$ ), depending on the bacterium and the experimental conditions tested. After $18 \mathrm{~h}$, no growth inhibitions were observed.

Escherichia coli (Fig. 2a-i) showed significant growth inhibitions after treatment with L-PRP, L-PRP cryo or P-PRP for up to $4 \mathrm{~h}$ when $10^{4}$ and $10^{5} \mathrm{CFU} / \mathrm{ml}$ were seeded (Friedman-Anova test: $\mathrm{p}<0.05$, at least) (Fig. 2a, b, d, e, g, h), but not at $10^{6} \mathrm{CFU} / \mathrm{ml}$ (Fig. 2c, $\mathrm{f}, \mathrm{i})$. Whatever the PRP preparation, at $10^{4} \mathrm{CFU} / \mathrm{ml}$ a decreasing inhibiting effect was observed between 1 and $4 \mathrm{~h}$ of incubation (Fig. 2a, d, g) and between 2 and $4 \mathrm{~h}$ only with L-PRP cryo (Fig. $2 \mathrm{~d}$ ). When increasing the concentration of bacteria, the growth inhibition was similar independently of the incubation time.

Decreased growth inhibitions were also observed with increasing bacterial concentrations after $1 \mathrm{~h}$ on the same preparation (Friedman-Anova test: $\mathrm{p}<0.05$, at least) (Fig. 2a-c; d-f; g-i). This decrease was particularly evident between $10^{4}$ (Fig. 2a, c) and $10^{6} \mathrm{CFU} / \mathrm{ml}$ (Fig. 2g, i), following incubation with L- and P-PRP. No significant differences were observed among the preparations.
Staphylococcus aureus (Fig. 3) was significantly inhibited for at least up to $4 \mathrm{~h}$, independently of the preparation tested or the number of seeded bacteria (Friedman-Anova test: $\mathrm{p}<0.01$, at least) (Fig. 3a-i). For almost all the experimental conditions, the inhibition of growth was similar during the first two hours of incubation (Fig. 3a-h), whereas it decreased between 1 and $4 \mathrm{~h}$ (Fig. 3a, c-i) and between 2 and 4 h (Fig. 3a-i), excluding $10^{5} \mathrm{CFU} / \mathrm{ml}$ bacteria treated with L-PRP (Fig. 3b). Independently of the preparation, increasing concentrations of bacteria underwent similar inhibitions of growth when incubated for the same time.

L-PRP, L-PRP cryo and P-PRP induced similar growth inhibitions at $10^{4}$ and $10^{5} \mathrm{CFU} / \mathrm{ml}$ (Fig. 3a, d, g and $\mathrm{b}, \mathrm{e}, \mathrm{h}$ ) for each incubation time, whereas significant differences were observed at $10^{6} \mathrm{CFU} / \mathrm{ml}$ (Friedman-Anova test: $\mathrm{p}<0.02$, at least) (Fig. 3c, f, i).

Klebsiella pneumoniae did not show significant timedependent growth inhibition within each preparation for up to $4 \mathrm{~h}$ whatever the concentration of seeded bacteria (Fig. 4a-h), excluded P-PRP at $10^{6} \mathrm{CFU} / \mathrm{ml}$ (Friedman-Anova test: $\mathrm{p}<0.02$ ) (Fig. 4i). Within each preparation, different growth inhibitions were observed among the three bacterial concentrations after 1, 2 and $4 \mathrm{~h}$ with L-PRP (Fig. $4 \mathrm{a}-\mathrm{c}$ ), after 2 and $4 \mathrm{~h}$ with L-PRP cryo (Fig. 4d-f) and after 1 and $2 \mathrm{~h}$ with P-PRP (Friedman-Anova test: $\mathrm{p}<0.05$, at least) (Fig. 4g-i). Significant differences were also observed comparing the preparations after 1 and $2 \mathrm{~h}$ when seeding $10^{4} \mathrm{CFU} / \mathrm{ml}$ (Fig. 4a, d, g), but only after $1 \mathrm{~h}$ at higher bacterial concentrations (Fig. 4b, e, h and c, f, i) (Friedman-Anova test: $\mathrm{p}<0.05$ ).

Pseudomonas aeruginosa showed significant growth inhibition with time, when $10^{4}$ (Fig. 5a, d, g) and $10^{5} \mathrm{CFU} / \mathrm{ml}$ (Fig. 5b, e, h) were seeded (Friedman-Anova test: $\mathrm{p}<0.01$, at least), independently of the preparations. Growth inhibition differences were observed between 1 (Fig. 5a, b, d) and $4 \mathrm{~h}$ of incubation (Fig. 5e, g, h) and between 2 and $4 \mathrm{~h}$ (Fig. 5b, e, g). No growth differences were found when $10^{6} \mathrm{CFU} / \mathrm{ml}$ were seeded (Fig. 5c, f, i). After incubation with L-PRP and L-PRP cryo, similar growth inhibitions were observed among the bacterial concentrations on the same time, whereas a significant decrease was found after $2 \mathrm{~h}$ of incubation with P-PRP (Friedman-Anova test: $\mathrm{p}<0.05$ ) (Fig. 5g-i). No significant differences of growth inhibition were observed among the preparations.

Enterococcus faecalis growth was inhibited by all the preparations for up to $4 \mathrm{~h}$ of incubation, whatever the bacterial concentrations tested (Friedman-Anova test: $\mathrm{p}<0.01$, at least) (Fig. 6a-i). Differences were observed between 1 and $4 \mathrm{~h}$ when $10^{4} \mathrm{CFU} / \mathrm{ml}$ were seeded with L-PRP cryo and P-PRP (Fig. 6d, g); at $10^{5} \mathrm{CFU} / \mathrm{ml}$ with L-PRP and P-PRP (Fig. 6b, h) and at $10^{6} \mathrm{CFU} / \mathrm{ml}$ 


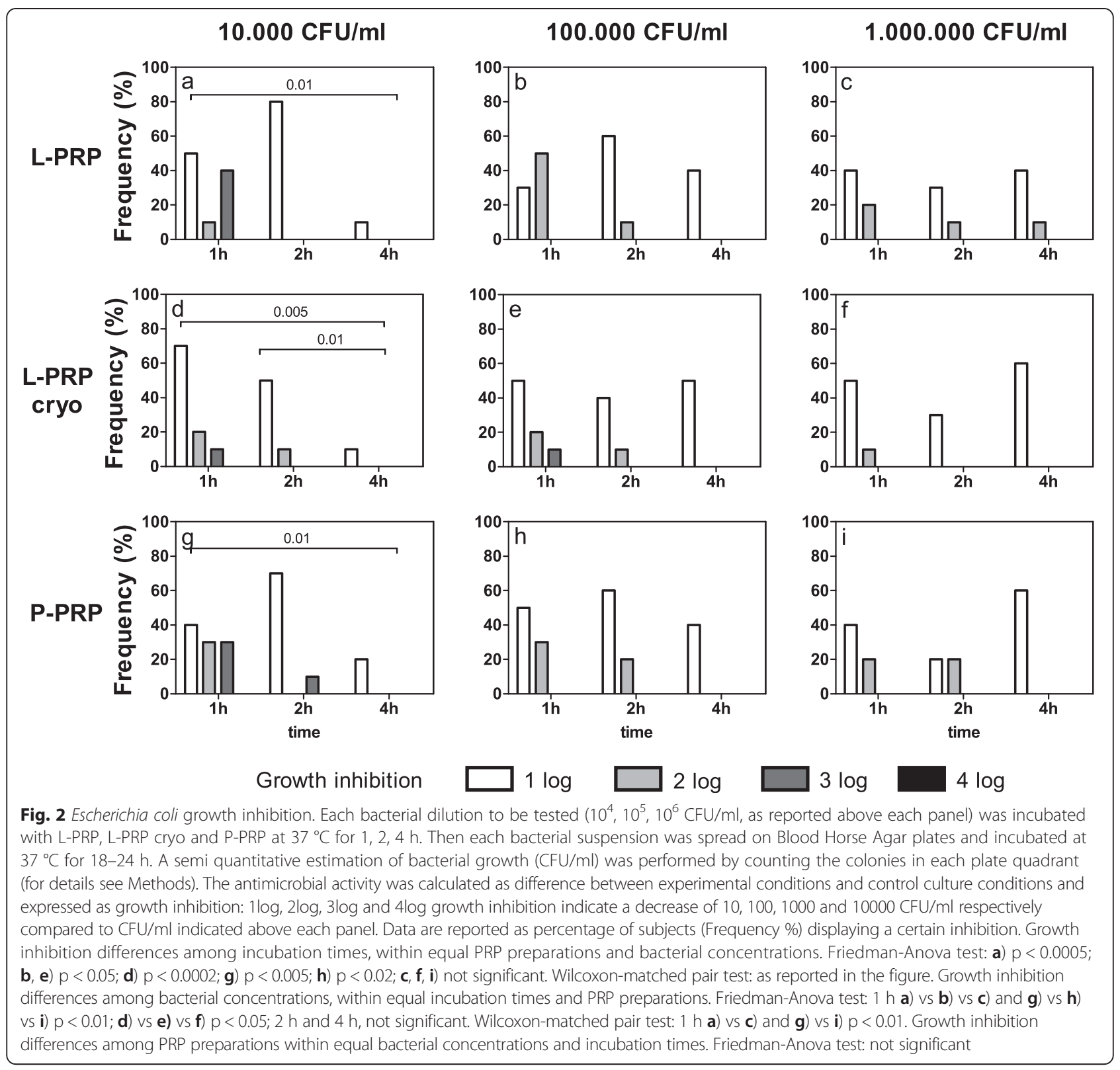

with all the preparations (Fig. 6c, f, i). Moreover, differences of growth inhibition were observed between 1 and $2 \mathrm{~h}$ when $10^{4} \mathrm{CFU} / \mathrm{ml}$ were seeded with P-PRP (Fig. 6g) and when $10^{6} \mathrm{CFU} / \mathrm{ml}$ were incubated with L-PRP cryo and P-PRP (Fig. 6f, i). Between 2 and 4 h, inhibition was evident at $10^{5} \mathrm{CFU} / \mathrm{ml}$ incubated with L-PRP and P-PRP (Wilcoxon-matched pair test: $\mathrm{p}<0.01$, at least) (Fig. 6b, h) and at $10^{6} \mathrm{CFU} / \mathrm{ml}$ incubated with P-PRP (Wilcoxon-matched pair test: $\mathrm{p}<0.001$ ) (Fig. 6i). Independently of the preparation, significant variations among the different bacterial concentrations were found after 2 and $4 \mathrm{~h}$ of incubation with L-PRP and L-PRP cryo and only after $4 \mathrm{~h}$ with P-PRP (Friedman-Anova test: $\mathrm{p}<0.05$, at least) (Fig. 6a-c, d-f and g-i), with significant differences between $10^{5}$ and $10^{6} \mathrm{CFU} / \mathrm{ml}$ after $2 \mathrm{~h}$ of incubation with L-PRP cryo (Fig. $6 e, f$ ). The comparison among the three plasma fractions evidenced a decreasing inhibiting activity (from L-PRP to P-PRP) following the incubation of $10^{5} \mathrm{CFU} / \mathrm{ml}$ at $2 \mathrm{~h}$ (Friedman-Anova test: $\mathrm{p}<0.05$ ) (Fig. 6b, e, h).

\section{Microbicidal protein evaluation}

The concentrations of the main soluble factors, described as microbicidal proteins, were different among the three PRP preparations (as determined by Friedman-Anova test: 


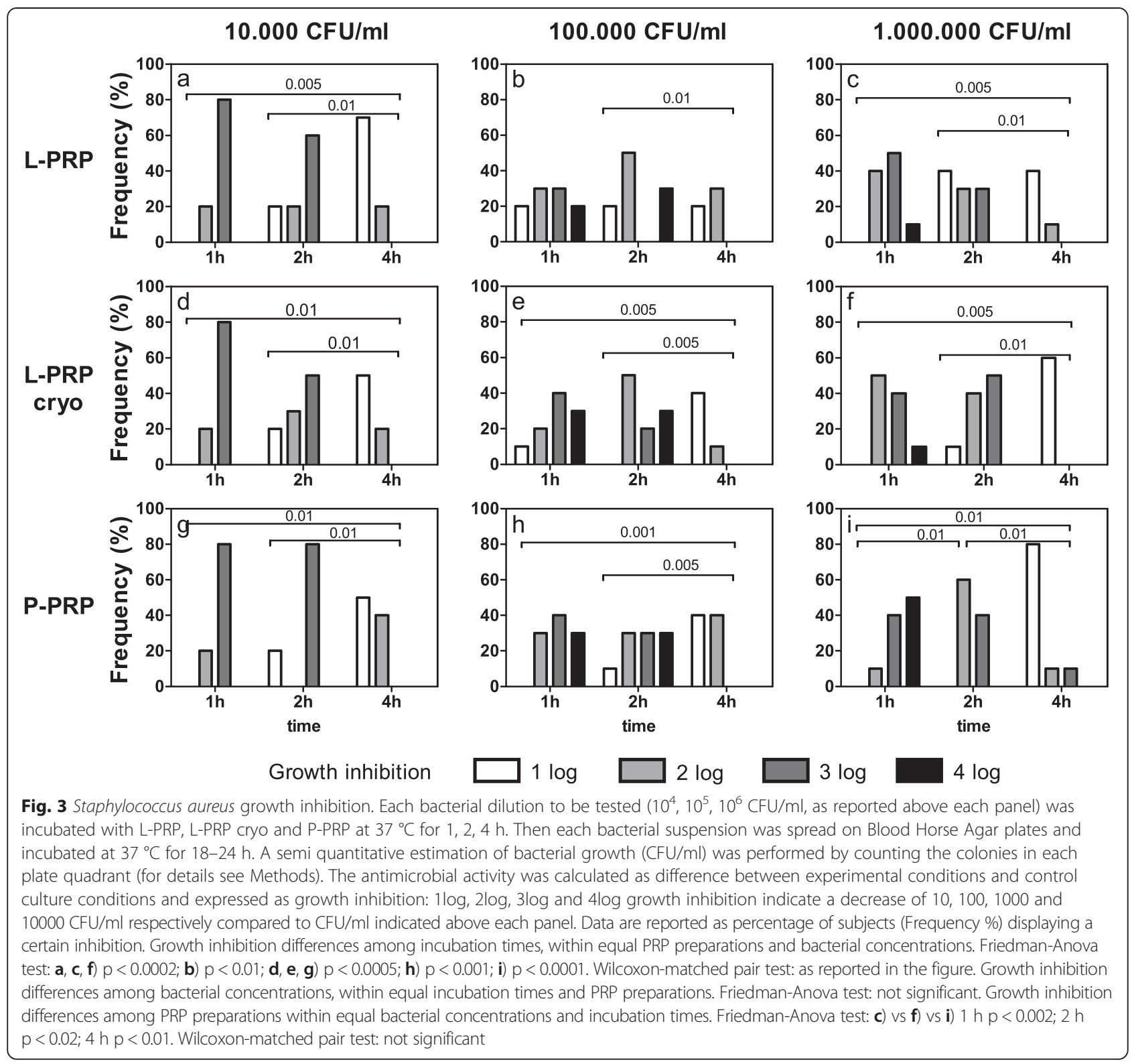

$\mathrm{p}<0.02$, at least) (Fig. 7a-d, g), excluded NAP-2 and SDF-1 $\alpha$ (Fig. 7e, f), whose concentrations were similar.

In general, the molecules were more concentrated in L-PRP (MIP-1 $\alpha$, RANTES, GRO- $\alpha$, IL- 8 and IL-6) and in L-PRP cryo (RANTES, GRO- $\alpha$, IL-8 and IL-6) than in P-PRP (Wilcoxon-matched pair test: $\mathrm{p}<0.02$ at least).

The concentrations of RANTES, GRO- $\alpha$ and IL- 8 were stable after cryopreservation, whereas they were slightly decreased in MIP-1 $\alpha$ and IL-6 (Wilcoxon-matched pair test: $\mathrm{p}<0.02$ ), as determined by the comparison between L-PRP and L-PRP cryo.

After $18 \mathrm{~h}$ of activation, IL-8, RANTES and GRO- $\alpha$ concentrations increased in all the preparations, whereas NAP-2 and SDF- $1 \alpha$ were stable (data not shown). IL-6 concentration increased only in L-PRP and L-PRP cryo, whereas MIP-1 $\alpha$ increased in L-PRP and P-PRP, but not L-PRP cryo (data not shown).

For all the bacteria, we evaluated the correlation between bacterial growth inhibition (induced by the three PRP preparations obtained by each donor after 1, 2 and $4 \mathrm{~h}$ of incubation) and the concentration of microbicidal proteins released by the matched PRP preparations after $1 \mathrm{~h}$ of activation (Table 2). It was not possible to analyze the corresponding correlations after $18 \mathrm{~h}$, since the bacteria reached an overgrowth phase.

The concentrations of the molecules considered (MIP-1 $\alpha$ / CCL3, RANTES/CCL5, GRO- $\alpha$ /CXCL1, NAP-2/CXCL7, IL-8/CXCL8, SDF-1 $\alpha / C X C L 12$ and IL-6) were strongly 


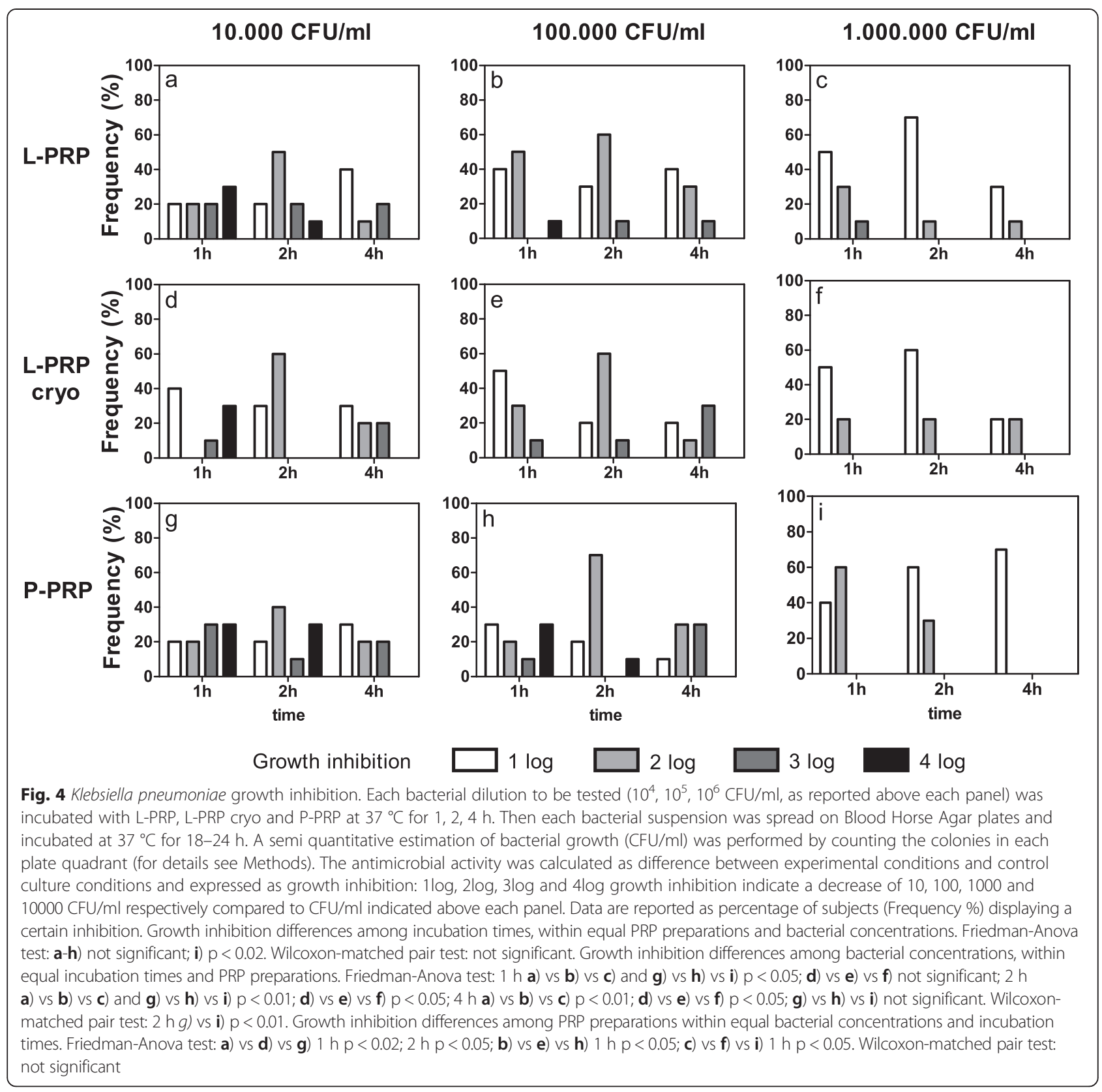

correlated to bacterial growth inhibition, mainly from the second hour of incubation (Table 2).

Escherichia coli inhibition showed correlations with RANTES, GRO- $\alpha$ and SDF- $1 \alpha$ concentrations (KendallTau rank correlation: $\mathrm{p}<0.05$, at least). Staphylococcus aureus inhibition correlated with the concentrations of all the molecules excluded IL-6 (Kendall-Tau rank correlation: $\mathrm{p}<0.05$, at least), whereas Klebsiella pneumoniae, Pseudomonas aeruginosa and Enterococcus faecalis inhibition correlated with the concentrations of all the microbicidal molecules considered (Kendall-Tau rank correlation: $\mathrm{p}<0.05$, at least).

\section{Discussion}

In this study, the antibacterial activity of L-PRP (leukocyte and platelet-rich plasma) and P-PRP (pure platelet-rich plasma) was evaluated against five bacteria strains (Escherichia coli, Staphylococcus aureus, Klebsiella pneumoniae, Pseudomonas aeruginosa, Enterococcus faecalis). The contribution of leukocytes and the preservation of the biological properties after freezing were also evaluated.

We found a time-dependent inhibition of bacteria growth, for up to $4 \mathrm{~h}$, at low bacterial numbers in Escherichia coli and Pseudomonas aeruginosa and at 


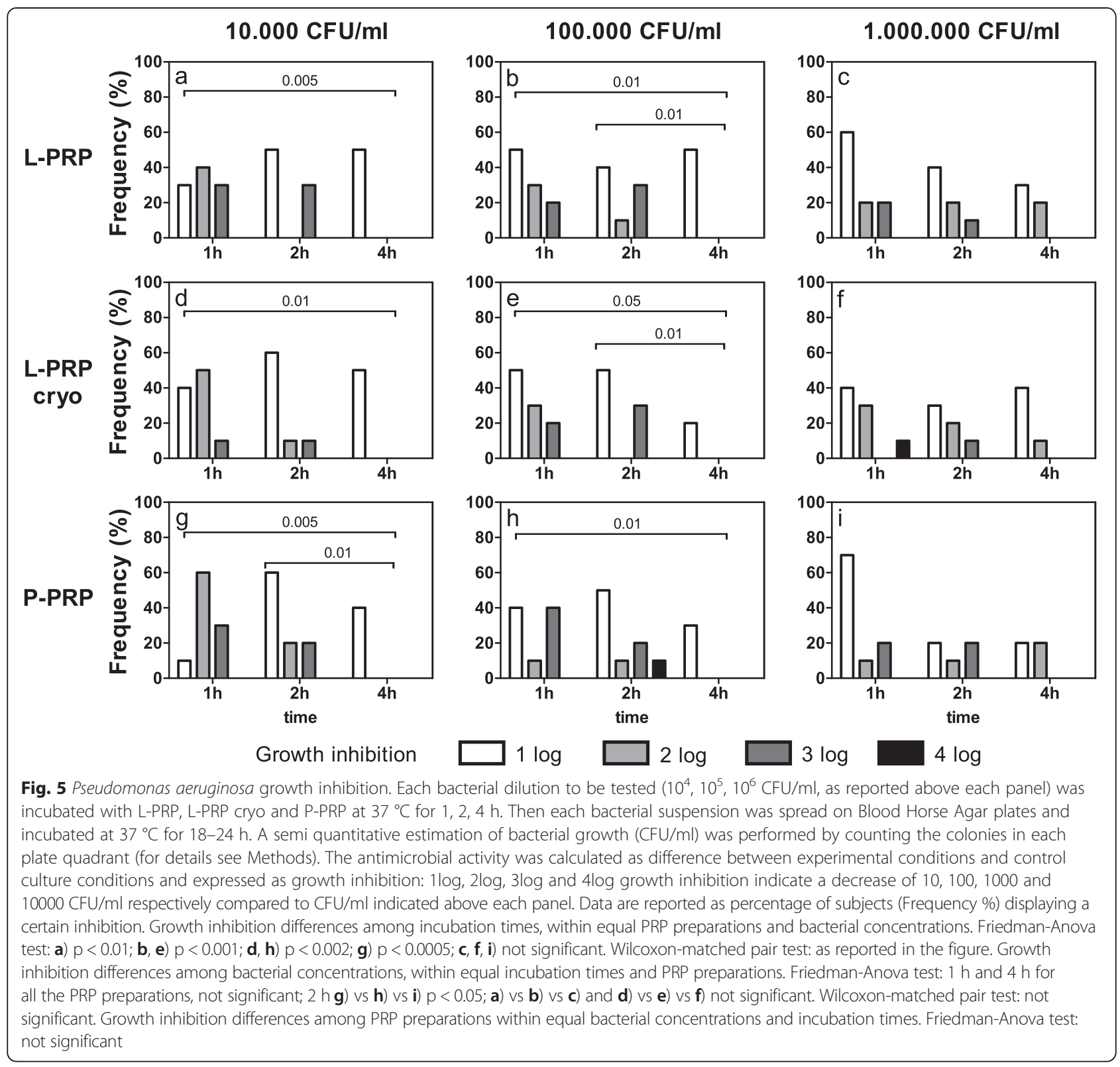

higher numbers in Staphylococcus aureus and Enterococcus faecalis, after treatment with the three plasma fractions (L-PRP, L-PRP cryo or P-PRP). Klebsiella pneumoniae was the only strain not showing a time-dependent inhibition of growth whatever bacterial concentration and PRP preparation.

The loss of antibacterial effect displayed by all the preparations after $18 \mathrm{~h}$ suggests a short-term and not complete microbicidal activity at the experimental concentrations tested, and/or that the amount of microbicidal proteins present in PRP preparation is not sufficient to limit the bacteria growth for a long time, which gives important indications for the early prophylactic use of PRP in the clinical practice.
Previous data have shown that analogous PRP formulations, enriched in leukocytes, had similar antimicrobial effects against Escherichia coli [22, 25], Staphylococcus aureus [22-24] and Pseudomonas aeruginosa [25], whereas the data concerning Klebsiella pneumoniae are not univocal, thus indicating both partial [25] and lack of susceptibility [22].

The analysis of the distribution of growth inhibitions (as indicated by log values) identified Staphylococcus aureus and Klebsiella pneumoniae as the most susceptible bacteria, which underwent a decrease of $10.000 \mathrm{CFU} / \mathrm{ml}(4$ logarithms of growth inhibition) in various experimental conditions. Since these two strains are well-known for their strong resistance to antibiotics [37, 38], the present 


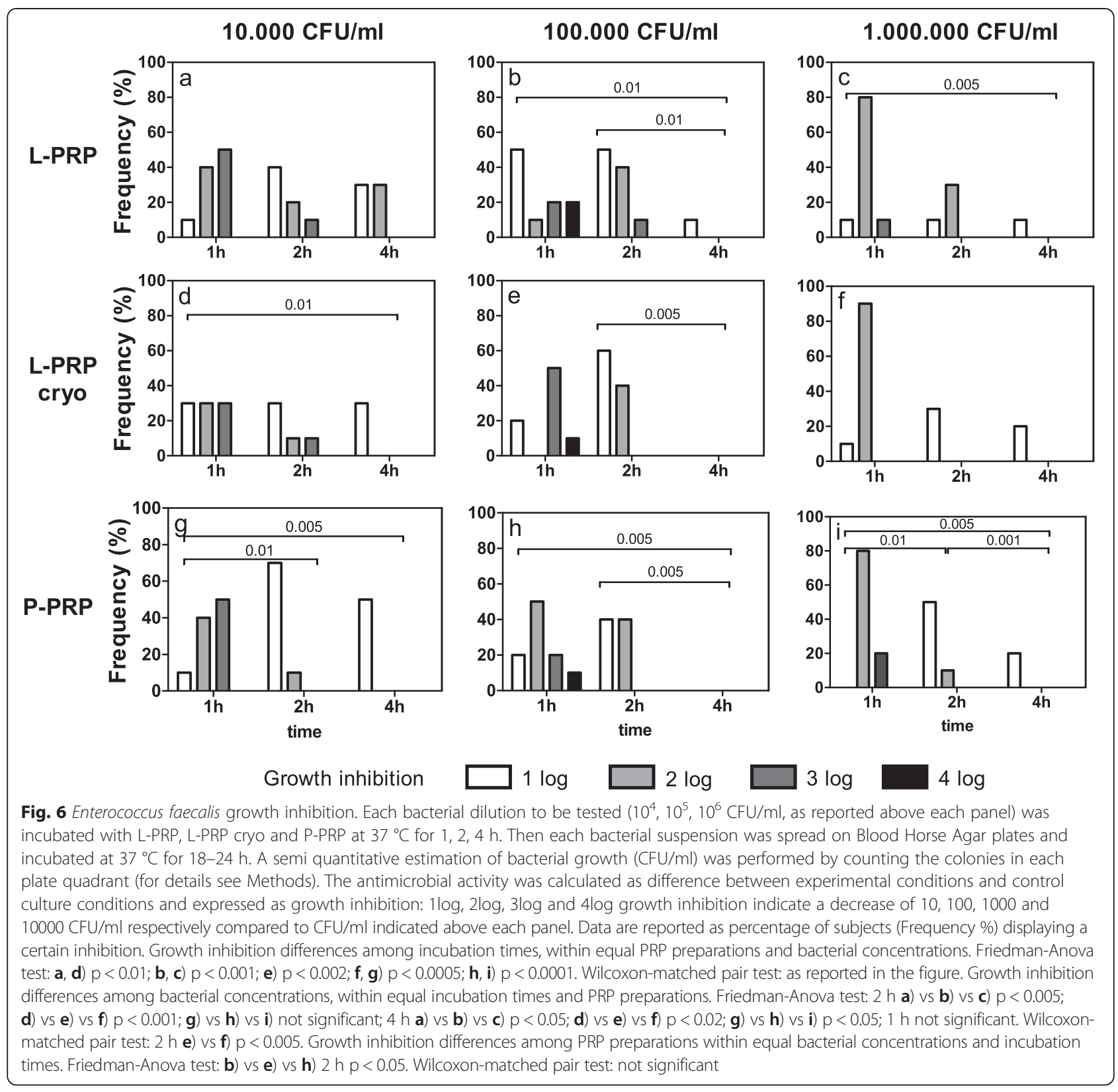

results are particularly relevant for the early prophylaxis against possible bacterial contaminations during clinical applications of PRP.

The similar microbicidal activity displayed by both L-PRP and L-PRP cryo, against all the strains considered, demonstrated the maintenance of the antimicrobial properties of L-PRP even after freezing and opens the possibility for cryopreserving this preparation. PRP containing only platelets was found to maintain coagulation ability, platelet morphology, P-selectin expression and growth factor release after some hours at room temperature [39]. The cryopreservability for up to 3 months of the main proteins involved in ocular surface healing [40] and their potential use as an alternative to fetal bovine serum for the cryo-preservation of human mesenchymal stem cells [41] were also reported. Furthermore, it was recently described that the freeze-thawing storage procedure did not affect the anabolic effects on different cell types [17].

To our knowledge, this is the first description of the preservation of microbicidal properties following freezing and these data are of particular interest, considering the possibility of a single preparation of self-derived platelet products to be used in consecutive administrations for therapeutic purposes. 


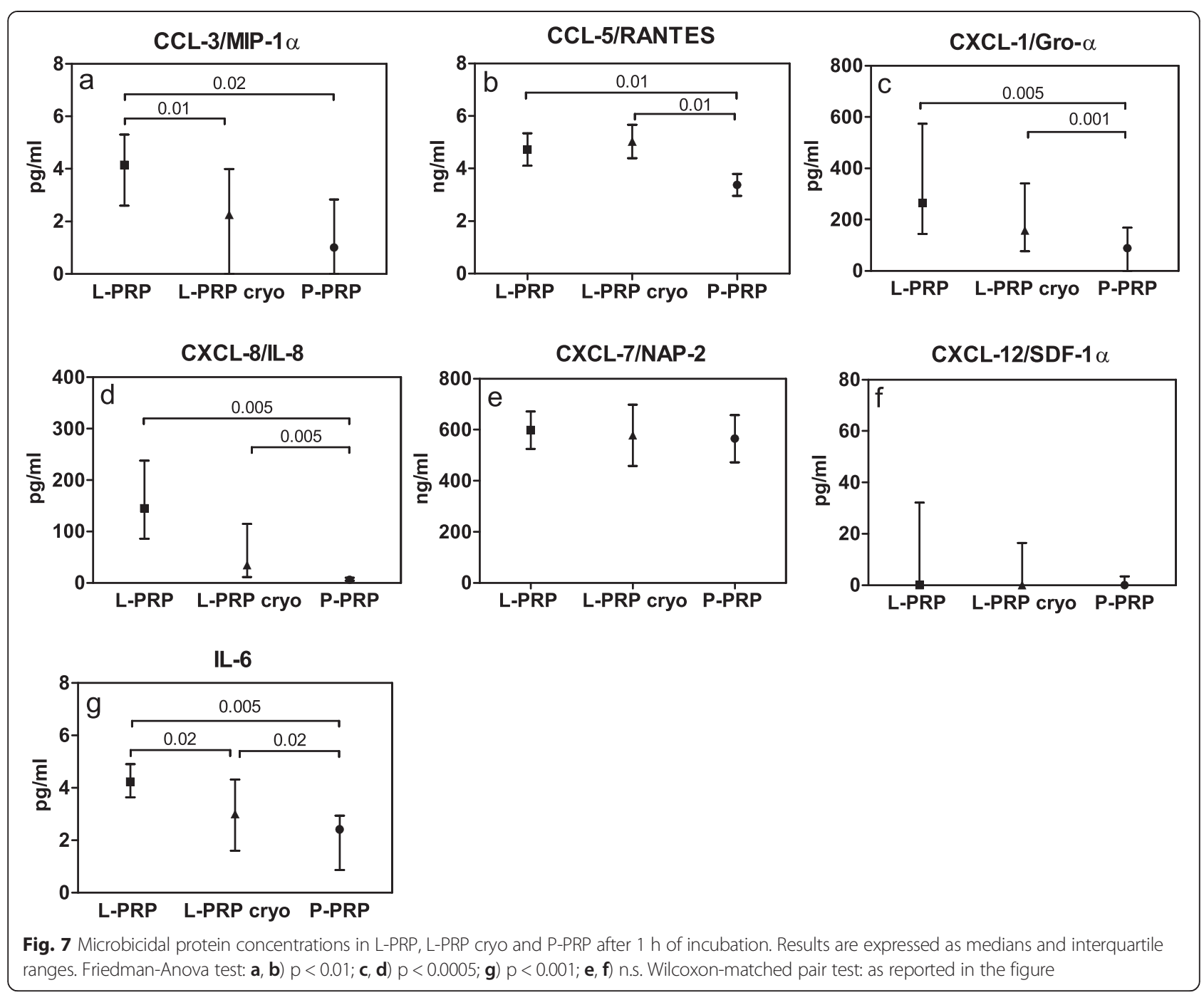

The inclusion and the possible role played by leukocytes in different PRP preparations have been variously debated during the last decades. Previous studies have shown mixed results, some reporting that concentrated delivery of leukocytes to a site of injury may amplify the release of anabolic and pro-inflammatory mediators [42], whereas others sustaining that leukocytes enhance the release of growth factors and anti-inflammatory mediators, thus possibly playing an important antibacterial role. Indeed, although leukocytes have been proposed as an additional source for cytokines, microbicidal proteins and myeloperoxidase activity [43], nowadays the few available published data do not support the increased microbicidal activity of PRP due to the leukocyte component [22-24]. In particular, no correlation between microbicidal activity and the number of either platelets or leukocytes in PRP preparations used against the same strains we tested and between myeloperoxidase activity and bacterial killing of PRP preparations against
Staphylococcus aureus were observed [22, 23]. Furthermore, two PRP products, containing or lacking the leukocyte component, showed similar antimicrobial activities [24]. In agreement, we found that the bacterial growth inhibition was similar among the three plasma fractions, thus strongly suggesting that the presence of leukocytes does not supply a substantial improvement in the antibacterial potential in PRP, with the main effects probably due to platelet microbicidal molecules.

Considering this aspect, we evaluated the correlation between bacterial growth inhibition and the concentration of some soluble factors displaying microbicidal activity $[12,13]$. Among these, MIP-1 $\alpha$, RANTES, GRO- $\alpha$, IL-8, NAP- 2 and SDF- $1 \alpha$ are the most common, with molecular structures of classical chemokines and therefore called "kinocidins", for their dual role as chemokines and microbicidal effectors $[8,13]$.

We obtained interesting results concerning further correlations among Escherichia coli, Klebsiella pneumoniae and 
Table 2 Correlations between bacterial growth inhibition and soluble factors

\begin{tabular}{|c|c|c|c|c|c|c|c|c|}
\hline \multirow[t]{2}{*}{ Bacteria } & \multirow[t]{2}{*}{ Time } & \multicolumn{7}{|l|}{ Soluble factors } \\
\hline & & CCL3/MIP-1a & CCL-5/RANTES & CXCL1/GRO-a & CXCL-8/IL-8 & CXCL-7/NAP2 & CXCL-12/SDF-1a & IL-6 \\
\hline \multirow[t]{3}{*}{ Escherichia coli } & $1 \mathrm{~h}$ & --- & --- & --- & --- & --- & $p<0.05$ & -- \\
\hline & $2 \mathrm{~h}$ & --- & $p<0.05$ & $p<0.05$ & --- & --- & $p<0.005$ & --- \\
\hline & $4 \mathrm{~h}$ & -- & -- & $p<0.01$ & --- & --- & --- & --- \\
\hline \multirow[t]{3}{*}{ Staphylococcus aureus } & $1 \mathrm{~h}$ & $p<0.01$ & --- & $p<0.0001$ & --- & $p<0.01$ & --- & --- \\
\hline & $2 \mathrm{~h}$ & $p<0.005$ & $p<0.01$ & -- & $p<0.01$ & $p<0.000005$ & $p<0.05$ & -- \\
\hline & $4 \mathrm{~h}$ & $p<0.005$ & $p<0.05$ & --- & $p<0.01$ & $p<0.00001$ & -- & -- \\
\hline \multirow[t]{3}{*}{ Klebsiella pneumoniae } & $1 \mathrm{~h}$ & --- & $p<0.000005$ & $p<0.01$ & $p<0.01$ & $p<0.001$ & $p<0.0001$ & $p<0.01$ \\
\hline & $2 \mathrm{~h}$ & $p<0.01$ & --- & --- & --- & --- & --- & --- \\
\hline & $4 \mathrm{~h}$ & $p<0.01$ & $p<0.05$ & --- & $p<0.005$ & $p<0.000005$ & $p<0.001$ & $p<0.005$ \\
\hline \multirow[t]{3}{*}{ Pseudomonas aeruginosa } & $1 \mathrm{~h}$ & --- & --- & --- & --- & --- & --- & --- \\
\hline & $2 \mathrm{~h}$ & $p<0.000005$ & $p<0.0005$ & & $p<0.01$ & $p<0.000005$ & $p<0.005$ & $p<0.0001$ \\
\hline & $4 \mathrm{~h}$ & $p<0.0005$ & $p<0.0005$ & $p<0.05$ & $p<0.005$ & $p<0.000005$ & $p<0.001$ & $p<0.0005$ \\
\hline \multirow[t]{3}{*}{ Enterococcus faecalis } & $1 \mathrm{~h}$ & --- & --- & --- & --- & $p<0.005$ & --- & --- \\
\hline & $2 \mathrm{~h}$ & $p<0.000005$ & $p<0.00005$ & $p<0.05$ & $p<0.001$ & $p<0.0005$ & $p<0.00005$ & $p<0.000005$ \\
\hline & $4 \mathrm{~h}$ & $p<0.05$ & --- & --- & -- & --- & --- & --- \\
\hline
\end{tabular}

Significant correlations between bacterial growth inhibition at different time points and the concentration of soluble factors released by the PRP preparations after $1 \mathrm{~h}$ of activation and described with antimicrobial potential, as determined by Kendall-Tau rank correlation test

Pseudomonas aeruginosa growth inhibition and MIP-1 $\alpha$, RANTES, GRO- $\alpha$ and IL-8 concentrations compared to previous preliminary data on a pure-PRP preparation [44]. Moreover, a new molecule (SDF-1 $\alpha$ ), previously not evaluated [44], showed correlations with Escherichia coli growth inhibition. In different in vitro experiments, strong antimicrobial effects against Escherichia coli were found for GRO- $\alpha$ but not for RANTES, although the authors used recombinant peptides at micromolar concentrations [12]. Native chemokine concentrations in serum are basically in the picomolar to nanomolar range [45], as we detected in plasma concentrates, therefore a lack of concordance with results proposed by Yang [12] might be attributable to the use of synthetic proteins instead of native molecules. In addition, since we detected significant differences of RANTES concentrations among the three PRP preparations, the lack of correlation observed with Escherichia coli inhibition [44] suggests the need for a threshold level for RANTES to be effective as microbicidal protein. Moreover, as this chemokine possesses chemotactic activity in vivo, we can speculate a microbicidal loop in which the presence of RANTES in injected PRP directly inhibits Escherichia coli growth and simultaneously amplifies the response by attracting and recruiting leukocytes into the sites of inflammation.

MIP- $1 \alpha$, RANTES and GRO- $\alpha$ concentrations were confirmed to correlate with growth inhibition of Staphylococcus aureus, Pseudomonas aeruginosa and Enterococcus faecalis [44]. In addition, we found that MIP-1 $\alpha$, RANTES, GRO- $\alpha$ and IL- 8 were involved in the inhibition of
Klebsiella pneumoniae, whereas IL-8 was involved in the inhibition of Pseudomonas aeruginosa. All these chemokines showed concentrations increasing from P-PRP to L-PRP, therefore suggesting a concentrationdependent effect of these factors on bacterial growth inhibition.

Three new molecules (NAP-2, SDF-1 $\alpha$ and IL-6) considered displayed strong correlations with growth inhibition of almost all the bacterial analyzed.

The neutrophil-activating peptide (NAP)-2 is a derivative of platelet basic protein (PBP), which is itself part of the platelet microbicidal proteins (PMPs). NAP-2 is also well-known as activator of neutrophils (activity shared with the homologous IL- 8 and GRO- $\alpha$ chemokines). After platelet activation, NAP-2 is released and processed at the $\mathrm{N}$-terminal part, finally reaching the active form as neutrophil activating peptide (NAP-2) [46]. During infections, proteolytic activation of NAP-2 and neutrophil attraction lead to an amplified response, resulting in bacterial killing [47].

SDF (stromal cell-derived growth factor)- $1 \alpha$ is a small chemokine, usually induced after stimulus with lipopolysaccharide (a large molecule contained in the Gram negative cell wall bacteria) [48]. SDF-1 $\alpha$ is involved in chemotaxis and is also considered to be the main chemo attractant factor for the stem cells [49]. Its modulation was proposed to be a useful therapeutic strategy for the stimulation of tissue repair. The present results, showing correlations between SDF- $1 \alpha$ concentrations and the growth inhibition of all the bacteria tested, open the possibility to consider this molecule as an important component 
within PRP preparations, thus displaying a double role both as prophylactic molecule against invading microorganisms and regulator of stem cell mobilization and therefore tissue remodeling, considering the clinical use of PRP.

IL-6 is a cytokine, secreted by macrophages and T cells [50], thus displaying an important role in host defense and possibly during infections associated to antibiotic resistant microorganisms, such as Klebsiella pneumoniae and Enterococcus faecalis. In fact, it has been demonstrated that IL-6 is involved in resistance to Streptococcus pneumoniae infection in a mouse model and the knockout of the IL-6 gene, inducing an increase in the levels of proinflammatory (TNF $\alpha$, IL-1 $\beta$, IFN- $\gamma$ ) and ant-inflammatory (IL-10) cytokines [51], resulted in the mouse's premature death. Although the mechanisms by which IL-6 contributes to antibacterial activity are still not clear, the role of IL-6 against infection is commonly acknowledged [52].

Results presented in the present study, showing a strong correlation between IL-6 concentrations and Klebsiella pneumoniae, Pseudomonas aeruginosa and Enterococcus faecalis growth inhibition, support the role of IL-6 against bacterial infections.

\section{Conclusions}

In conclusion, we have shown the in vitro antibacterial activity of L-PRP and P-PRP against five different bacterial strains and the possibility to cryopreserve L-PRP, without important changes in its effectiveness, thus allowing a single preparation to be used for multiple in vivo administrations. Furthermore, we did not find significant differences in microbicidal activity between preparations containing leukocytes before and after storage conditions, thus highlighting potential clinical uses for therapeutic protocols, including soft tissue and orthopedic surgery, or for the prevention of local infections.

The prevalent role of MIP- $1 \alpha$, RANTES, GRO- $\alpha$ and IL-8 as mediators of bacterial inhibition was confirmed. In addition, the microbicidal contribution in vitro of three new molecules (NAP-2, SDF-1 $\alpha$ and IL-6) was highlighted.

Results in the present study supply basic information about the most common molecules recognized as microbicidal effectors and released by platelets and leukocytes during immunological responses, however there are obvious limitations compared to in vivo conditions, where a complexity of physiological networks and molecular mechanisms take place. Indeed, the initial in loco antimicrobial activity of some platelet-stored and leukocytederived chemokines contained in PRP, may be supported by the chemotactic recruitment of specific cellular populations and their interaction might amplify different prophylactic responses against infection agents and trigger specific immunological pathways.

\section{Abbreviations}

AMP: Anti-Microbial Peptides; $\mathrm{CaCl}_{2}$ : Calcium Chloride; CFU: Colony-Forming Units; CXCL: Chemokine (C-X-C motif) Ligand; GRO-a: Growth-regulated protein homolog alpha; IL-6: Interleukin-6; IL-8: Interleukin-8; MIP-1a: Macrophage Inflammatory Protein-1-alpha; NAP-2: Neutrophil-Activating Protein-2; PMP: Platelet Microbicidal Proteins; PPP: Platelet-Poor Plasma; PRP: Platelet-Rich Plasma; P-PRP: Pure Platelet-Rich Plasma; L-PRP: Leukocytes- and platelet-rich plasma; RANTES: Regulated on activation, normal T cell expressed and secreted; SDF-1a: Stromal cell-derived factor 1-alpha.

\section{Competing interests}

The authors declare that they have no competing interests.

\section{Authors' contributions}

EM and GF conceived, designed and coordinated the study and revised the draft of the manuscript. VC carried out the evaluation of proteins, collected data, carried out the statistical analyses and drafted the manuscript. LC performed multiplex test, $\mathrm{ABe}$ and $\mathrm{ABi}$ carried out bacteria cultures. MPL supervised microbiological evaluations. EK and EM supervised clinical procedures. BDM performed the selection of subjects and collected blood. All the authors contributed to text revision and gave final approval for publication.

\section{Acknowledgements}

This work was supported by grants from Rizzoli Orthopaedic Institute (Ricerca Corrente), " $5 \times 1000$ " funds to EM, University of Bologna (RFO funds to EM), Italian Ministry of Health (Project RF-2009 grant no. 1498841 to EM, EK) and Emilia-Romagna Region (Region-University Program 2010-2012: Regenerative Medicine of Cartilage and Bone to EM, EK, MM).

The authors thank Mr. Keith Smith for English editing, Mrs. Patrizia Rappini and Graziella Salmi for manuscript typing and Alice Roffi, BScD, for helping in P-PRP preparation.

\section{Author details}

'Laboratory of Immunorheumatology and Tissue Regeneration/RAMSES, Rizzoli Orthopaedic Institute, Via di Barbiano 1/10, 40136 Bologna, Italy. ${ }^{2}$ Department of Medical and Surgical Sciences, University of Bologna, Bologna, Italy. ${ }^{3}$ Laboratory of Biomechanics and Technology Innovation/ NABI, 2nd Orthopaedic and Traumatologic Clinic, Rizzoli Orthopaedic Institute, via di Barbiano 1/10, Bologna, Italy. ${ }^{4}$ Unit of Clinical Microbiology, St. Orsola University Hospital, University of Bologna, Bologna, Italy.

Received: 18 December 2014 Accepted: 13 July 2015

Published online: 30 July 2015

\section{References}

1. Klinger $\mathrm{MH}$, Jelkmann W. Role of blood platelets in infection and inflammation. J Interferon Cytokine Res. 2002;22:913-22.

2. Tschon M, Fini M, Giardino R, Filardo G, Dallari D, Torricelli $P$, et al. Lights and shadows concerning platelet products for musculoskeletal regeneration. Front Biosci (Elite Ed). 2011;3:96-107.

3. Anitua E, Aguirre JJ, Algorta J, Ayerdi E, Cabezas Al, Orive G, et al. Effectiveness of autologous preparation rich in growth factors for the treatment of chronic cutaneous ulcers. J Biomed Mater Res B Ap Biomater. 2008;84:415-21.

4. Anitua E, Sanchez M, Orive G. Potential of endogenous regenerative technology for in situ regenerative medicine. Ad Drug Deliv Rev. 2010;62:741-52.

5. Cole BJ, Seroyer ST, Filardo G, Bajaj S, Fortier LA. Platelet-rich plasma: where are we now and where are we going? Sports Health. 2010;2:203-10.

6. Filardo G, Presti ML, Kon E, Marcacci M. Nonoperative biological treatment approach for partial Achilles tendon lesion. Orthopedics. 2010;33:120-3.

7. Kerrigan SW, Cox D. Platelet-bacterial interactions. Cell Mol Life Sci. 2010;67:513-23.

8. Yeaman MR. Platelets in defense against bacterial pathogens. Cell Mol Life Sci. 2010;67:525-44.

9. Yeaman MR. Bacterial-platelet interactions: virulence meets host defense. Future Microbiol. 2010;5:471-506.

10. Semple JW, Italiano Jr JE, Freedman J. Platelets and the immune continuum Nat Rev Immunol. 2011;11:264-74.

11. Wiesner J, Vilcinskas A. Antimicrobial peptides: the ancient arm of the human immune system. Virulence. 2010;1:440-64. 
12. Yang D, Chen Q, Hoover DM, Staley P, Tucker KD, Lubkowski J, et al. Many chemokines including CCL20/MIP-3alpha display antimicrobial activity. J Leukoc Biol. 2003;74:448-55

13. Yount NY, Waring AJ, Gank KD, Welch WH, Kupferwasser D, Yeaman MR Structural correlates of antimicrobial efficacy in IL-8 and related human kinocidins. Biochim Biophys Acta. 1768;2007:598-608.

14. Wasterlain AS, Braun HG, Dragoo JL. Contest and formulations of platelet-rich plasma. Operative Techni Orthop. 2012;22:33-42.

15. Ehrenfest DMD, Sammartino G, Shibli JA, Wang H, Zou D, Bernard J. Guidelines for the publication of articles related to platelet concentrates (Platelet-Rich Plasma - PRP, or Platelet-Rich Fibrin - PRF): the international classification of the POSEIDO. Poseido J. 2013;1:17-28.

16. Cieslik-Bielecka A, Dohan Ehrenfest DM, Lubkowsha ABT. Microbicidal properties of leukocyte and platelet-rich plasma/fibrin (L-PRP/L-PRF): new perspectives. J Biol Regul Homeost Agents. 2012;26:43S-52S

17. Roffi A, Filardo G, Kon E, Marcacci M. Does PRP enhance bone integration with grafts, graft substitutes, or implants? A systematic review. BMC Musculoskelet Disord. 2013;14:330.

18. Filardo G, Kon E, Roffi A, Di Matteo B, Merli ML, Marcacci M. Platelet-rich plasma: why intra-articular? A systematic review of preclinical studies and clinical evidence on PRP for joint degeneration. Knee Surg Sports Traumatol Arthrosc. 2013. [E-pub ahead of print]

19. Filardo G, Kon E, Di Matteo B, Pelotti P, Di Martino A, Marcacci M. Platelet-rich plasma for the treatment of patellar tendinopathy: clinical and imaging findings at medium-term follow-up. Int Orthop. 2013;37:1583-9.

20. Perdisa F, Filardo G, Di Matteo B, Marcacci M, Kon E. Platelet rich plasma: a valid augmentation for cartilage scaffolds? A systematic review. Histol Histopathol. 2014;29:805-14.

21. Filardo G, Kon E, Di Matteo B, Di Martino A, Tesei G, Pelotti P, et al. Platelet-rich plasma injections for the treatment of refractory Achilles tendinopathy: results at 4 years. Blood Transfus. 2014;12:533-40.

22. Bielecki TM, Gazdzik TS, Arendt J, Szczepanski T, Krol W, Wielkoszynski T. Antibacterial effect of autologous platelet gel enriched with growth factors and other active substances: an in vitro study. J Bone Joint Surg (Br). 2007;89:417-20.

23. Moojen DJ, Everts PA, Schure RM, Overdevest EP, Van ZA, Knape JT, et al Antimicrobial activity of platelet-leukocyte gel against Staphylococcus aureus. J Orthop Re. 2008;26:404-10.

24. Anitua E, Alonso R, Girbau C, Aguirre JJ, Muruzabal F, Orive G. Antibacterial effect of plasma rich in growth factors $\left(\mathrm{PRGF}^{\circledR}\right.$-Endoret $\left.{ }^{\oplus}\right)$ against Staphylococcus aureus and Staphylococcus epidermidis strains. Clin Exp Dermatol. 2012;37:652-7.

25. Burnouf T, Chou ML, Wu YW, Su CY, Lee LW. Antimicrobial activity of platelet (PLT)-poor plasma, PLT-rich plasma, PLT gel, and solvent/ detergent-treated PLT lysate biomaterials against wound bacteria. Transfusion. 2013;53:138-46.

26. Drago L, Bortolin M, Vassena C, Taschieri S, Del Fabbro M. Antimicrobia activity of pure platelet-rich plasma against microorganisms isolated from oral cavity. BMC Microbiol. 2013;13:47.

27. Assirelli E, Filardo G, Mariani E, Kon E, Roffi A, Vaccaro F, et al. Effect of two different preparations of platelet-rich plasma on synoviocytes. Knee Surg Sports Traumatol Arthrosc. 2014. [E-pub ahead of print]

28. Cavallo C, Filardo G, Mariani E, Kon E, Marcacci M, Pereira Ruiz MT, et al. Comparison of platelet-rich plasma formulations for cartilage healing: an in vitro study. J Bone Joint Surg Am. 2014;96:423-9.

29. Lautenbach E, Patel JB, Bilker WB, Edelstein PH, Fishman NO Extended-spectrum beta-lactamase-producing Escherichia coli and Klebsiella pneumoniae: risk factors for infection and impact of resistance on outcomes. Clin Infect Dis. 2001;32:1162-71.

30. Zalavras CG, Patzakis MJ, Holtom P. Local antibiotic therapy in the treatment of open fractures and osteomyelitis. Clin Orthop Relat Res. 2004:427:86-93

31. Anitua E, Orive G, Aguirre JJ, Andia I. Five-year clinical evaluation of short dental implants placed in posterior areas: a retrospective study. J Periodontol. 2008;79:42-8.

32. Perut F, Filardo G, Mariani E, Cenacchi A, Pratelli L, Devescovi V, et al. Preparation method and growth factor content of platelet concentrate influence the osteogenic differentiation of bone marrow stromal cells. Cytotherapy. 2013;15:830-9.
33. Mariani E, Cattini L, Neri S, Malavolta M, Mocchegiani E, Ravaglia G, et al. Simultaneous evaluation of circulating chemokine and cytokine profiles in elderly subjects by multiplex technology: relationship with zinc status. Biogerontology. 2006;7:449-59.

34. Mariani E, Neri S, Cattini L, Mocchegiani E, Malavolta M, Dedoussis GV, et al Effect of zinc supplementation on plasma IL-6 and MCP-1 production and NK cell function in healthy elderly: interactive influence of +647 MT1a and -174 IL-6 polymorphic alleles. Exp Gerontol. 2008;43:462-71.

35. Mader JT, Calhoum J. Osteomyelitis. In: Mandell GL, Bennet JE, Dolin R, editors. Principles of Infectious Diseases. Philadelphia: Churchill Livingston; 2000. p. 1182-96.

36. Prabhakara R, Harro JM, Leid JG, Harris M, Shirtliff ME. Murine immune response to a chronic Staphylococcus aureus biofilm infection. Infect Immun. 2011;79:1789-96

37. Bush K. New beta-lactamases in gram-negative bacteria: diversity and impact on the selection of antimicrobial therapy. Clin Infect Dis. 2001;32:1085-9.

38. Kang Cl, Kim SH, Park WB, Lee KD, Kim HB, Kim EC, et al. Bloodstream infections due to extended-spectrum beta-lactamase-producing Escherichia coli and Klebsiella pneumoniae: risk factors for mortality and treatment outcome, with special emphasis on antimicrobial therapy. Antimicrob Agents Chemother. 2004:48:4574-81.

39. Bausset O, Giraudo L, Veran J, Magalon J, Coudreuse JM, Magalon G, et al. Formulation and storage of platelet-rich plasma homemade product. Biores Open Access. 2012;1:115-23.

40. Anitua E, Muruzabal F, Pino A, Merayo-Lloves J, Orive G. Biological Stability of Plasma Rich in Growth Factors Eye Drops After Storage of 3 Months. Cornea. 2013:32:1386.

41. Murphy MB, Blashki D, Buchanan RM, Yazdi IK, Ferrari M, Simmons PJ, et al. Adult and umbilical cord blood-derived platelet-rich plasma for mesenchymal stem cell proliferation, chemotaxis, and cryo-preservation. Biomaterials. 2012;33:5308-16.

42. Yuan $\mathrm{T}$, Zhang $\mathrm{CQ}$, Wang $\mathrm{JH}$. Augmenting tendon and ligament repair with platelet-rich plasma (PRP). Muscles Ligaments Tendons J. 2013;3:139-49.

43. Hampton MB, Kettle AJ, Winterbourn CC. Involvement of superoxide and myeloperoxidase in oxygen-dependent killing of Staphylococcus aureus by neutrophils. Infect Immun. 1996;64:3512-7.

44. Mariani E, Filardo G, Canella V, Berlingeri A, Bielli A, Cattini L, et al. Platelet-rich plasma affects bacterial growth in vitro. Cytotherapy. 2014;16:1294-304.

45. Yung SC, Murphy PM. Antimicrobial chemokines. Front Immunol. 2012;3:276

46. Nguyen LT, Kwakman PH, Chan DI, Liu Z, De BL, Zaat SA, et al. Exploring platelet chemokine antimicrobial activity: nuclear magnetic resonance backbone dynamics of NAP-2 and TC-1. Antimicrob Agents Chemother. 2011;55:2074-83.

47. Zlotnik A, Yoshie $\mathrm{O}$. The chemokine superfamily revisited. Immunity. 2012;36:705-16.

48. Sipert CR, Morandini AC, Modena KC, Dionisio TJ, Machado MA, Oliveira SH, et al. CCL3 and CXCL12 production in vitro by dental pulp fibroblasts from permanent and deciduous teeth stimulated by Porphyromonas gingivalis LPS. J Appl Oral Sci. 2013;21:99-105.

49. Garlet GP. To heal or not to heal? Chemokines as determinants of constructive or destructive inflammatory microenvironments. J Appl Oral Sci. 2013;21

50. Hack CE, De Groot ER, Felt-Bersma RJ, Nuijens JH, Strack Van Schijndel RJ, Eerenberg-Belmer AJ, et al. Increased plasma levels of interleukin-6 in sepsis. Blood. 1989:74:1704-10.

51. Van der Poll T, Keogh CV, Guirao X, Buurman WA, Kopf M, Lowry SF. Interleukin-6 gene-deficient mice show impaired defense against pneumococcal pneumonia. J Infect Dis. 1997;176:439-44.

52. Jones SA. Directing transition from innate to acquired immunity: defining a role for IL-6. J Immunol. 2005;175:3463-8. 